\title{
E-Blood Bank Application using GPS and Cloud Computing
}

\author{
Saranya, Shri Vindhya, Pushpa B
}

\begin{abstract}
In numerous elective cases, similar to mishaps, there might be Associate in Nursing basic might want for explicit blood gathering. When contrasted with the extent connection of interest of the blood awfully less amount of people blessing the blood, hence the need of the blood will increment. Blood Donation and intromission Services (BTS) are essential for sparing individuals' lives. Blood donation centers endure visit lack of blood; in this manner, commercials are frequently observed on informal communities encouraging sound individuals to blessing blood for patients $U N$ organization frantically need intromission. The E-Blood Bank is Associate in Nursing robot application that allows the client to go looking contributors of explicit individuals bolstered their area, in a short measure of your time. This application won't exclusively demonstrate the rundown of contributors anyway also facilitated with trailing the circumstance of the close to benefactors and giving SMS cautions to them, all together that the patient will be presented with blood a little while later. in order to blessing blood through the application, one must enroll himself by giving all the ideal subtleties. These subtleties ought to be substantial and valid all together that they'll be caterpillar-followed at the hour of crisis. when all the learning is acknowledged by the Admin, the benefactor will be extra to the rundown of enrolled contributors. GPS module is encased to discover the givers. Accordingly, exclusively enrolled individuals, UN office need to blessing blood, ready to get to the administration. Cloud-basically based administrations are prove horribly significant in basic blood conveyance as they care ready to focal and quick access to giver's information and site from wherever and whenever.
\end{abstract}

Watchwords: Cloud Computing, GPS, robot Application..constraints.

\section{INTRODUCTION:}

Now-a-days, give chains are frightfully troublesome than at any other time. Shoppers' anticipate new item, though associations, must be constrained to be extra imaginative however attributable to these changed escape clauses and shifted interruptions it still unequipped for agreeably tending to a few reasonable, real world challenges.

Revised Manuscript Received on December 30, 2019.

* Correspondence Author

Saranya, Assistant Professor, Department of Computer Science and Engineering,Saveetha School of Engineering, Saveetha Institute of Medical and Technical Sciences, Thandalam, Chennai, Tamilnadu, India602105.Saranya.cse01@gmail.com

Shri Vindhya, Associate Professor, Department of Computer Science and Engineering ,Saveetha School of Engineering, Saveetha Institute of of Medical and Technical Sciences, Thandalam, Chennai, Tamilnadu, India602105.Shrivindhyaa.sse@saveetha.com

Pushpa B, Assistant Professor,Department of Bio-Medical Engineering,Saveetha Institute of Medical and Technical Sciences,Thandalam,Chennai,Tamilnadu,India-602105 pushpaazhagesan@gmail.com

(C) The Authors. Published by Blue Eyes Intelligence Engineering and Sciences Publication (BEIESP). This is an open access article under the CC BY-NC-ND license (http://creativecommons.org/licenses/by-nc-nd/4.0/)
One among the premier fundamental test for example to deliver a quick assistance inside the crisis things, anyway a few of the administrations neglects to achieve it. By creating Associate in Nursing application which can encourage society and differed necessitous people is that the use of EBlood Bank which can give a quick support of the necessitous people. during this application the client's area will be caterpillar tracked exploitation GPS framework. On the off chance that blood is required, the benefactor with the ideal explicit individuals is known and informed concerning its interest. The venture comprises of equation that tracks area of the contributors, distinguishes the givers UN organization ar close to the circumstance of requester and informs them as well. In the event that the known close to contributors aren't ready to blessing blood these days, at that point the extent of trailing the benefactors is increment The MIS of bank Bharat spares the name of the giver UN organization is giving blood, a novel id through that the giver will peruse his record, arcanum for getting to the record, date of birth of the contributor because of his age ought to be inside the change of 18-60 years, sex of the individual, individuals, weight, portable no, email id, address, city, state, last time once contributor given blood also once a pristine contributor enrolled himself as a benefactor. This undertaking comprises of Associate in Nursing robot application that is blessing on the givers' Associate in Nursing droid-telephone application which can encourage to create a crisis administrations to the necessitous blood requestor looking for people for giving the blood and it furthermore uses cloud administrations for keeping the data of benefactor's securely.

\section{EXISTING SYSTEM}

Existing System We accumulate some of the data concerning the bank the executives framework situated around the local area and geographic district we find some of the medical clinics have its very own bank unit with each and every one specialized offices in a very town anyway this physical marvel is poor inside the geographic locale [2].

There are assortment of examination work is done to incorporate distributed computing, wellbeing area, and web based life. In existing frameworks, the given individuals and sum is investigate for inside the cloud data, any place the bank information has been hang on. when the outcomes are discovered, they're shown on the site for the medical clinic to check [1]. 


\section{E-Blood Bank Application using GPS and Cloud Computing}

The outcomes contain the major information of the blood donation centers that have that particular individual, requested by the land nearness. Regardless of the attainable quality of the potential blood benefactors close to 100 percent of the entire Indian populace gives blood. Progression in life science has misrepresented the blood request. Likewise, blood-contributors in some cases don't return to handle concerning the need for blood. These causes motivate North American country to grow a predominant framework which will help this blood gift framework

2.1: Drawbacks of the overall System A giver was giving a blood for capacity at a bank or the other community for transfusion to Associate in Nursing obscure beneficiary. These will happen at assortment of areas just as blood gift focuses, portable camps, versatile vans, and so on. There assortment of sorts 2.2 E-Blood Bank Application Using GPS and Cloud Computing

of blood gifts like intentional blood gift engineer [3]. this can be the sheltered and quality blood gift administration in light of the fact that the blood variety from willful non-repaid blood contributors is well-considered to be the most secure. in order to fortify intentional blood gift in creating nations like Bharat depends on wellcharacterized structures and operational guide for associations for this imperative movement Hardly any downsides of the overarching System 1) Cannot get the blood on time as the givers are from different areas. 2) Extra administrative works. 3) Error taking care of is never again productive thinking about that information are kept up physically. 4) Data the board transforms into dull as the documents increment. 5) Time consuming.

2.3 Motivation behind the E-Blood bank: A framework will be grown in fact which are utilized whenever put in should in any case be a legitimate speculation for the association. The framework is financially conceivable. It needn't bother with any further equipment or bundle. Since the interface for this strategy is created abuse the overall assets and innovations available, there's ostensible consumption and monetary practicableness without a doubt. The anticipated framework gives simple availability to bank framework, and it'll encourage all through crisis administrations. The framework can anyway closest bank consequently steady with that client can ready to check closest one in partner degree crisis.

\section{PROPOSED SYSTEM}

Proposed System User Registration In this part the client should bear the enlistment strategy during which he should fill his subtleties like name, enrolled address, contact run, individuals, age, furthermore he should fill his restorative data inside the sort. Solicitation Blood This is the second enhance that the client UN office is popular of blood can got the opportunity to demand blood by giving the important part like required individuals, contact scope of the client, current area of client (which are gotten by the apparatus naturally), when mentioned, the rundown of the nearby givers can get showed and also are informed. Blood Donor This is the third enhance that contributor can get the notice of the blood solicitation of the nearby blood requestor (user).and the contact subtleties of the requestor are shown on the apparatus. but this the benefactor can even give the blood whenever on this may, by abuse the apparatus. Proposed Algorithm Problem Description: This standard registers bank application. Information: ID, Password, is that the of character kind. Yield: Outcome is Notification to the giver and Response to the requestor from E-blood donation center application. E-Blood Bank Application Step 1: If User is enlisted then outfit User (ID) and secret key (Password) else Create new record; Step 2: If there is demand from purchaser for blood, music region of individual with GPS; Step three Check If blood benefactor is accessible to send the warning from $E$ blood bank programming to close by enrolled Donors. Stage 4: If GPS of the individual is no longer ON then ship the warning dependent on enrolled address. Stage 5: Check requirements for blood gift like HB, Weight, various variables, and past Blood Donation Date. Stage 6: If conditions are comfortable to acknowledge it. Stage 7: If Conditions are never again delighted at that point transport the warning to different contributors who are close by and furthermore qualified. Expected Results

- The quickest route for reaching the necessary Blood Donors.

- Reduction in the Corruption factor in Blood Bank.

- Direct Communication Between the contributor and the character needing blood During the Emergency Period.

\section{ARCHITECTURE DIAGRAM}

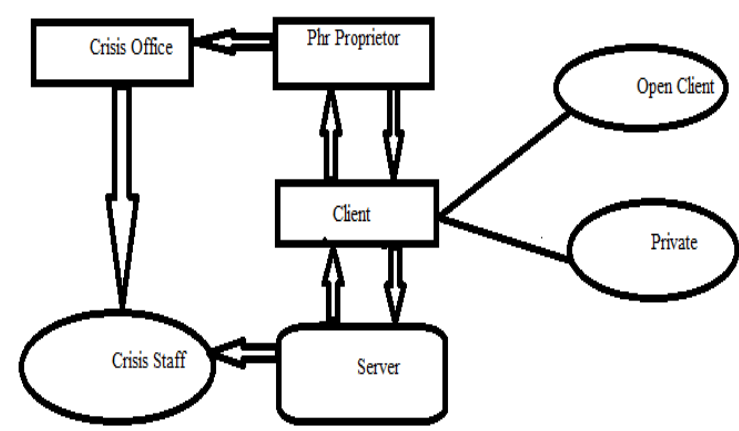

To guarantee the patients' administration over access to their very own PHRs, it's a promising procedure to encode the PHRs before redistributing. The framework is novel patientdriven structure and a lot of components for data get to the board to PHRs keep in semi-confided in servers s.to acknowledge ne-grained and ascendible learning access the executives for PHRs, framework influence characteristic based encoding (ABE) strategies to encode each patient's quality. 
The framework is gives the fine-grained get to the executives to the framework by abuse the different quality based encoding plans.

during this framework, the clients are classed into 2 security spaces known as Personal Security Domain and open security Domain. The clients like individuals from the family, companions are encased inside the individual space and thusly the clients from the human services association and protection later are thinking about on the grounds that the data clients from the overall population space. For each the 2 entirely unexpected arrangement of client area the varieties of trait based encoding is utilized. For the private security area the reversible Key-strategy characteristic based encoding subject is utilized. For the overall population security space the Multiple-Authority characteristic topic is arranged

\section{PERFORMANCE ANALYSIS}

\section{Anticipated RESULTS}

$\square$ The quickest path for reaching the necessary Blood

Benefactors.

$\square$ Reduction in the Corruption factor in Blood Bank.

Direct Communication Between the contributor and theindividual needing blood During the Emergency .

There are additionally scarcely any highlights which can be incorporated with this framework to make it progressively adaptable. Underneath list demonstrates the future focuses to be consider.

1. In future we will give the office to utilize our site in pc too as in cell phone moreover.

2. We will incorporate greater usefulness according to client necessity.

3. It contain all data about the blood donation center and furthermore appear the client can look by their blood prerequisite.

4. Surveys are taken until Application satisfies clients' necessity. After execution it is anything but difficult to oversee

5. The application and is anything but difficult to fathom the challenges. In this prerequisite are satisfy.

6. And furthermore it show blood donation center rundown and all data.

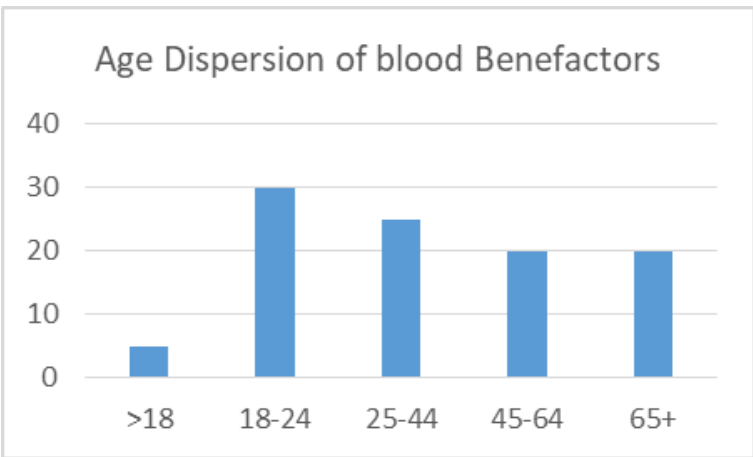

Age groups(years)

\begin{tabular}{|c|c|c|c|c|c|c|}
\hline \multicolumn{4}{|c|}{ Number of Procedure } & \multicolumn{3}{|c|}{ Percentage of Procedure } \\
\hline Transfusion of & $0-19$ yrs & $\begin{array}{l}45- \\
69 \\
\text { yrs }\end{array}$ & $85+$ & $\begin{array}{l}0- \\
19 \\
\text { yrs }\end{array}$ & $\begin{array}{l}45- \\
69 \\
\text { yrs }\end{array}$ & $85+$ \\
\hline Whole blood & 121 & 291 & 301 & $4 \%$ & $9 \%$ & $12 \%$ \\
\hline Red blood cells & 4,086 & 5,160 & 7,904 & $2 \%$ & $12 \%$ & $20 \%$ \\
\hline Leukosytes & 123 & 220 & 228 & $6 \%$ & $7 \%$ & $18 \%$ \\
\hline Platelets & 126 & 210 & 218 & $\begin{array}{l}16 \\
\%\end{array}$ & $12 \%$ & $15 \%$ \\
\hline $\begin{array}{l}\text { Antologous } \\
\text { Blood }\end{array}$ & 12 & 20 & 30 & $1 \%$ & $2 \%$ & $5 \%$ \\
\hline
\end{tabular}

\section{CONCLUSION}

End the proposed machine bears Android essentially based utility which is particularly useful at Emergency Services for instance at the hour of Blood Transfusion, Blood Donation, etc. The machine offers a higher technique to converse with blood Donors. It is also prepared to keep up the database of the enlisted Donor's. It additionally shows ponder the contemporary science used in creating android essentially based limits

\section{REFERENCES}

1. Akh Khan and M.S. Alone" A New Concept of Blood Bank Management System utilizing Cloud Computing Rural. (On the web): 2290-2675 and Computer Engineering 3(1): 20-30(2012).

2. Android Based Blood Bank Application" Volume 1 Issue 910Page 890-910, 2013, ISSN 2385-1671

3. Smart Blood Bank Management Service"- (IORS-JCE) e-ISSN: 22760675, p-ISSN: 2290-8792, Volume 20, Issue 4, Ver. I (Mar-Apr. 2013), PP 171-156.

4. National Conference on Networks, Intelligence and Computing Systems || March 2016 Published by IJIRTS 112 Computer Aided Emergency Service System.

5. American Journal of Engineering (AJE) e-ISSN: 2330-0827 p-ISSN: 2340-0956 Volume-02, Issue-03, pp-106-109-Android Blood Donor Life Saving Application

6. International Journal of Innovations in Technology. (C) 2016, All Rights Reserved Page | 220 ISSN: 2455-130X Impact factor: 4.440 (Volume2, Issue2)

7. Asian Journal of Transfusion Science are given here kindness of Med know Publications Asian J Transfuse Sci. 2010 July; 3(1): 57-60.doi: 10.4102/0945-6290.53871 N. Choud.

8. Management Information System in Blood Bank ViksKulsh, 2, Dr Maheshwari International Journal of Engineering and Science ISSN: 2278-4721, Vol. 1, Issue 12(December 2012), PP 05-07

9. Priyadharshni, V. Saranya sri, S. Shabana devi, Kavitha "The Optimization of Blood Donor Information " International Journal of Innovative Research in Science, (IRJET) e-ISSN: 2340-0078 Volume: 06 Issue: 03| Feb-2015www.irjet.net p-ISSN: 2385-0065 (C) 2014, IRJET | Impact Factor esteem: 6.174 | ISO 9001:2008 Certified Journal | Page 275 Building, and Technology. An ISO 3280: 2008Certified Organization, Volume 3, Special Issue 1, February 2015.

10. Chandrani Chowdhury A Survey of Cloud-Based Health Care System" (An ISO 3280: 2097 Certified Organization) Vol. 3, Issue 4, August 2015. 


\section{E-Blood Bank Application using GPS and Cloud Computing}

\section{AUTHOR'S PROFILE}

Saranya, Assistant Professor, Department of Computer Science and Engineering,Saveetha School of Engineering, Saveetha Institute of Medical and Technical Sciences, Thandalam, Chennai, Tamilnadu, India-602105.

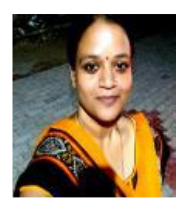

Shri Vindhya, Associate Professor, Department of Computer Science and Engineering ,Saveetha School of Engineering, Saveetha Institute of of Medical and Technical Sciences, Thandalam, Chennai, Tamilnadu, India-602105.

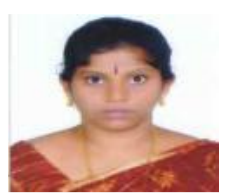

Pushpa B, Assistant Professor, Department of Bio Medical Engineering ,Saveetha School of Engineering, Saveetha Institute of of Medical and Technical Sciences, Thandalam, Chennai, Tamilnadu, India602105. 